Moersch's and Woltman's ${ }^{4}$ Iowa farmer (case 1) had a Nonne-positive CSF suggesting an increased autochthonous IgG production. Abnormal CCT findings were seen in one patient with the "jerking stiff man syndrome", ${ }^{5}$ but not in a second one, ${ }^{6}$ and in one typical case, ${ }^{3}$ comprising marked cerebellar atrophy and an enlarged fourth ventricle or enlarged basal cysterns, hypodense areas in the temporal lobes, and dilatation of the interhemispherical fissure. ${ }^{3}$

H-M MEINCK

K RICKER*

Neurologische Klinik

Oberer Eselsberg 45

D-7900 Ulm, FRG

*Neurologische Klinik,

Kopfklinikum.

Josef-Schneider-Straße 11,

D-8700 Würzburg, FRG

Accepted 2 April 1987

References

I Meinck HM, Ricker K, Conrad B. The stiff-man syndrome: new pathophysiological aspects from abnormal exteroceptive reflexes and the response to clomipramine, clonidine and tizanidine. $J$ Neurol Neurosurg Psychiatry 1984:47:280-7.

2 Whiteley AM, Swash M, Urich H. Progressive encephalomyelitis with rigidity. Brain 1976;99:27-42.

3 Maida E, Reisner T, Summer K, SandorEggerth H. Stiff-man syndrome with abnormalities in CSF and computerized tomography findings. Arch Neurol 1980;37:182-3.

4 Moersch FP, Woltman HW. Progressive fluctuating muscular rigidity and spasm ("stiff-man" syndrome): report of a case and some observations in 13 other cases. Mayo Clin Proc 1956;31:421-7.

5 Leigh PN, Rothwell JC, Traub M, Marsden CD. A patient with reflex myoclonus and muscle rigidity: "jerking stiff-man syndrome". J Neurol Neurosurg Psychiatry 1980:43:1125-31.

6 Alberca R, Romero M, Chaparro J. Jerking stiff-man syndrome. J Neurol Neurosurg Psychiatry 1982;45:1159-60.

The Miller Fisher syndrome following campylobacter enteritis: a report of two cases

The Miller Fisher syndrome is a rare variant of post infectious polyneuritis in which opthalmoplegia, areflexia and ataxia occur. We report two cases associated with campylobacter infection.

A 37 year old man had a 2 day history of diarrhoea 7 days after returning from hol- iday in Tenerife. A week later he noted parasthesiae in his hands and feet, followed over the next 5 days by diplopia, nasal regurgitation of fluids and difficulty in walking. There was no relevant past history. Systems enquiry was unhelpful. On examination he was apyrexial. The pulse rate was 80 per minute, the blood pressure $130 / 80 \mathrm{mmHg}$. There was complete bilateral external opthalmoplegia. The pupils were dilated with a sluggish response to light and accommodation; the fundi were normal. Bilateral lower motor neuron facial nerve palsies, absent gag reflexes, paralysis of the soft palate and bulbar dysarthria were noted. Muscle bulk, tone and power were normal apart from minimal weakness in the long extensors of his fingers. All deep tendon reflexes were absent with flexor plantar responses. The abdominal reflexes were retained. There was no sensory abnormality; proprioception and vibration were normal. Formal tests of coordination in the limbs were well performed but he demonstrated considerable ataxia of stance and gait. There were no other signs. Haematological and biochemical investigations were normal. There were no cells in the cerebrospinal fluid; the protein concentration was $0.54 \mathrm{~g} / \mathrm{l}$ and the glucose $4 \mathrm{mM} / \mathrm{l}(73 \mathrm{mg} / \mathrm{dl})$. Nerve conduction studies and computed tomography of his posterior fossa were normal. Campylobacter jejuni, sensitive to erythromycin, was grown from his stool. There was no other evidence of infection. A 5 day course of erythromycin cleared his stool of the organism. $\mathrm{He}$ required nasogastric feeding but did not suffer any respiratory embarassment. His neurological disability remained static for 10 to 14 days and thereafter rapidly improved. No definitive treatment other than the antibiotic was employed. Three months later he has returned to normal with no residual signs.

A 28 year old man had a 3 day episode of diarrhoea on holiday in Portugal. Ten days later he developed diplopia and parasthesiae over the anterior chest. His past history was unremarkable. On examination he was apyrexial. The pulse rate was 76 per minute, blood pressure $120 / 80 \mathrm{mmHg}$. There were bilateral sixth nerve palsies and impaired upward gaze. There were no other cranial nerve abnormalities. Muscle bulk and tone were normal. There was grade $4+/ 5$ weakness of shoulder abduction, wrist movements and finger extension bilaterally. Deep tendon reflexes in the arms were absent. Both knee and ankle jerks were present with flexor plantar responses. No sensory abnormality was detected; proprioception and vibration were preserved. No formal limb ataxia could be demonstrated, but he had ataxia of tandem gait. The rest of the examination was normal. Haematological and biochemical investigations were normal. The cerebrospinal fluid protein concentration was $0.36 \mathrm{~g} / \mathrm{l}$, the glucose $3.5 \mathrm{mM} / \mathrm{l}(64 \mathrm{mg} / \mathrm{dl})$; there were no cells on microscopy. Stool culture grew Campylobacter jejuni. Campylobacter antibody titres were $1 / 64$ (IgG 2.9 units, IgM 4.1 units of optical density) indicating a recent infection. ${ }^{2}$ Titres to parainfluenza fell from $1 / 128$ to $1 / 64$ in 7 days. There was no other evidence of infection. Nerve conduction studies (including " $F$ " waves), electroencephalography and computed tomography of his posterior fossa were normal. His condition improved over a period of 10 days without specific treatment. There were no respiratory or bulbar symptoms at any time. He remains well 18 months later.

There has been one report of Miller Fisher syndrome presenting with campylobacter enteritis. ${ }^{3}$ We report a further two cases associated with this organism. The neurological illness in these patients was preceded by a short episode of diarrhoea but there were no symptoms of enteritis ab presentation. One patient received antibioti $\mathscr{\Phi}^{+}$ therapy but both made full recoveries wit㗭 음 no other specific treatment. Retrospective evidence of campylobacter infection has $z$ been demonstrated in over a third of a recents series of patients with Guillain-Barré syno drome. $^{4}$ A history of diarrhoeal illness should be sought and asymptomatic camo pylobacter infection considered in patients presenting with these conditions. No comment can be made, however, on the possible efficacy of clearing the organism from the stool. There remains debate about the exact site of the lesions in Miller Fisher syndrome. ${ }^{5}$ The cranial nerve palsies and ataxia indicate brainstem pathology but the areflexia points to a peripheral component as well. The recognition of this syndrome is important as in spite of its alarming nature the course and outcome warrant an optimistic outlook.

TIM ROBERTS
AJAY SHAH
JG GRAHAM
INF MCQUEEN
Department of Neurology,
University Hospital of Wales,
Heath Park, Cardiff CF4 $4 X N, U K$

References

${ }^{1}$ Fisher M. An Unusual Variant of acute idiopathic polyneuritis (syndrome of 
opthalmoplegia, ataxia and areflexia). $N$ Eng J Med 1956;255:57-65.

2 Walker RI, Caldwell MB, Lee EC, Guerry P, Trust TJ, Ruiz-Palacios GM. Pathophysiology of campylobacter enteritis. Microbiol Rev 1986;50(1):81-94.

${ }^{3}$ Wroe SJ, Blumhardt LD. Acute polyneuritis with cranial nerve involvement following Campylobacter jejuni infection. J Neurol Neurosurg Psychiatry 1985;48:593.

${ }^{4}$ Kaldor I, Speed ER. Guillain-Barré syndrome and Campylobacter jejuni: a serological study. Br Med J 1984;288:1867-70.

5 Ropper AH. Unusual Clinical variants and signs in Guillain-Barré syndrome. Arch Neurol 1986;43(11):1150-2.

Accepted 2 April 1987

\section{Paraganglioma of the cauda equina}

Sir: Paraganglioma of the cauda equina is a rare tumour which was first described in 1972. ${ }^{1}$ Recently Anderson and Gullan ${ }^{2}$ reported the occurrence of this tumour in a 63 year old woman and commented on the small number of reported cases. We would like to document 2 more cases of paraganglioma of the cauda equina.

Case A was a 50 year old man who was referred to the University Hospital of Wales, with an 8 year history of back pain. In the year prior to admission the pain had become associated with paraesthesiae in the buttocks and legs, and he had developed hesitancy of micturition. The only positive physical signs on examination were absent tendon reflexes, and pain on movement of the lumbar spine. A radiculogram revealed a complete block to the downward flow of contrast at the L3 level. At operation a vascular tumour occupied most of the lumbar spinal canal. The tumour was adherent to the roots of the cauda equina. The tumour was excised except for a small amount of capsule adherent to the nerve roots. Postoperatively he was given a course of local radiotherapy. He was last seen 2 years after surgery, and was well with no further back pain.

Case B was a 38 year old man, who presented at the Dundee Royal Infirmary with a 6 month history of back pain, which radiated down the back of the thighs. The only abnormal physical signs were a positive bilateral femoral nerve stretch test, and mild weakness of the left quadriceps. A myelogram showed a rounded intradural mass at the L1 level. At operation the dura was opened to reveal a vascular mass mea- suring about $2 \mathrm{~cm}$, which was lightly adherent to the roots of the cauda equina. The tumour was completely excised. Post operatively he made a good recovery. He was last seen 6 months after surgery, and was well with no further back pain, and no neurological deficit.

Histological examination of the tumour from Case $A$ included examination of a smear preparation at the time of operation. The smear revealed separate groups of round to oval nuclei with eosinophilic cytoplasm, and occasional rosette formation. The appearances were quite similar to smear preparations of an ependymoma. Paraffin sections of the tumours revealed a vascular stroma, with nests and sheets of round to oval nuclei, with eosinophilic cytoplasm. A very occasional mitosis was evident in Case $A$, and there was no mitotic activity seen in Case B. A Grimelius stain demonstrated numerous neurosecretory granules within the cellular cytoplasm in both cases. Using a peroxidase labelled antibody system both tumours showed a strong positive reaction for neuron specific enolase. Electronmicroscopic examination revealed the presence of cytoplasmic membrane bound granules which measured between $800-1500 \AA$. The diagnosis of paraganglioma was made in both cases.

There have been few descriptions of smear preparations of these tumours, and it is of interest that the smear preparation from our Case A, and of that reported by Gaffney, Doorly and $\mathrm{Din}^{3}$ resembled an ependymoma. In this respect Anderson and Gullan emphasised the importance of making the correct diagnosis with regard to both prognosis and treatment. We have found 18 reported cases in the literature, ${ }^{1-17}$ which with the addition of our two cases brings the total to 20. We observe that all of these cases appear to have followed a benign course, but documentation and follow up remains important in furthering our knowledge of the long term behaviour of paraganglioma of the cauda equina. Male predominance is suggested for these tumours, since 14 of these cases were males.

$$
\begin{array}{r}
\text { G COLE } \\
\text { T VARMA* } \\
\text { M HOURIHAN } \\
\text { S SINGHRAO } \\
\text { K FRAZER } \\
\text { Departments of Pathology, } \\
\text { Neurosurgery, Radiology and Electron } \\
\text { Microscopic Unit, } \\
\text { University Hospital of Wales, } \\
\text { Cardiff CF4 4XN, UK } \\
\text { *Department of Neurosurgery, } \\
\text { Dundee Royal Infirmary, Dundee. }
\end{array}
$$

References

1 Lerman A, Kaplan E, Daman L. Ganglio- $\frac{D}{\bar{C}}$ neuroma paraganglioma of the intradural $\odot$ filum terminale. $J$ Neurosurg 1972;36:652-8.

2 Anderson JR, Gullan RW. Paraganglioma of the cauda equina: a case report. $J$ Neurol 0 Neurosurg Psychiatry 1987;50:100-3.

3 Gaffney EF, Doorly T, Dinn JJ. Aggressive, $\frac{\widehat{\rho}}{\supset}$ oncocytic neuroendocrine tumour (oncocytic paraganglioma) of the cauda equina $\overrightarrow{2}$ Histopathology 1986;10:311-9.

4 Horoupian D, Kerson L, Saiontz H, Valsamis M. Paraganglioma of the cauda equina $\stackrel{S}{+}$ clinicopathological and ultrastructural stud-O ies of an unusual case. Cancer 1974;33:음 1337-48.

5 Gullotta F, Helpap B. Tissue culture, electron $\overparen{\overparen{D}}$ microscopic and enzyme histochemical investigations of extra-adrenal paraganglioma. Pathol Eur 1976;11:257-64.

6 Russel D, Rubinstein LJ. Pathology of $\overrightarrow{0}$ Tumours of the Nervous System. 4th ed.London: Edward Arnold, 1977.

7 Van Alphen HAM, Bellot SM, Stam FC. Para-ब ganglioma of the cauda equina. Clin Neuro Neurosurg 1977;79:316-22.

8 Llena J. Paraganglioma in the cerebrospinali axis. In: Zimmerman HM, ed. Progress in Neuropathology. Vol 5. New York: Raven, $\overrightarrow{-}$ 1983:261-76.

9 Llena J, Hirano A, Rubin R. Paragangliomain $\overrightarrow{0}$ the cauda equina. Acta Neuropatiof 1979;46:235-7.

10 Llena J, Wisoff H, Hirano A. Gangliocticic paraganglioma in the cauda equima.J Neurosurg 1982;56:275-9.

11 Binkley W, Vakili S, Worth R. Paraganglionna of the cauda equina. $J$ Neurosurg 1920 56:275-9.

12 Cabello A, Ricoy J. Paraganglioma of 져음 cauda equina. Cancer 1983;52:751-4.

13 Soffer D, Pittaluga S, Caine Y, Feinsod $\vec{M} \cdot \overrightarrow{0}$ Paraganglioma of the cauda equina: a repor@ of a case and review of the literature. Cancer 1983;51:1907-10.

14 Taxy JB. Paraganglioma of the cauda equina report of a rare tumour. Cancer 1983;51금 1904-6.

15 Ilgren D, Teddy P. Paraganglioma of the caudå equina: case report. Clinical Neuropatho 1984;3:148-52.

16 Legace R, Delage C, Gagne F. Paragangliom of the filum terminale. Can $J$ Neurol Scit 1978;5:257-60.

17 Lipper S, Decker RE. Paraganglioma of the cauda equina. A histologic, immunohisto chemical and ultrastructural study and review of the literature. Surg Neurof 1984;22:415-26. Does the peripheral blood leukocyte count
predict the risk of transient ischaemic attacks
and strokes?

Sir: The peripheral blood leukocyte count has been shown to be a predictor of myo 